\title{
Una batalla sin armas. Caridad y beneficencia en lucha contra el conocimiento médico, durante la segunda mitad del siglo XIX en Lima
}

Recibido: 07.03.2019

Aprobado: 25.03.2019
Antonio Coello Rodríguez

Universidad Nacional Mayor de San Marcos

sequilao@gmail.com

\begin{abstract}
RESUMEN
En el presente trabajo de investigación se muestra mediante fuentes inéditas y editas la lucha ideológica en Lima durante la segunda mitad del siglo XIX entre la recientemente creada Facultad de Medicina de Lima (San Fernando) por dirigir y organizar una lucha por higienizar los hospitales y la ciudad contra el ente caritativo de la Sociedad de Beneficencia Pública de lima, una institución que velaba por la alimentación, educación y salud de los enfermos y desposeídos, pero que se amparaba en la caridad cristiana y no presentaba ningún aporte científico, tan solo asistencial representado por una comunidad de gente opulenta y rica que entrega sus bienes para la manutención de las clases menesterosas. Esta lucha ideológica estará apoyada, a su vez por la llegada al Perú de las Hermanas de la Caridad, quienes serán invitadas por la Sociedad de Beneficencia para hacerse cargo de los hospitales y brindar ayuda moral y espiritual a los enfermos, teniendo un enfrentamiento directo contra los médicos, la cual se plasmó en diario y revistas de la época.
\end{abstract}

Palabras clave: Hospitales, Lima, Salubridad, Higiene, Hermanas de la Caridad

\section{A battle without weapons. Charity and beneficense in the fight against medical knowledge. Lima: second half of the nineteenth century}

\begin{abstract}
The following research work uses unpublished and edit sources to show the ideological struggle in Lima during the second half of the nineteenth century between the recently created Faculty of Medicine of Lima (San Fernando) for leading and organizing a struggle to sanitize up the hospitals and the city against the charitable entity of the Society of Public Charity of Lima, an institution that watched over the food, education and health of the sick and dispossessed, but that was protected in Christian charity and did not present any scientific contribution, only welfare represented by a community of affluent and wealthy people who give their goods for the maintenance of the needy classes. This ideological struggle will be supported, also, by the arrival of the Sisters of Charity, in Peru, who will be invited by the Charity Society to be in charge of hospitals and provide moral and spiritual help to the sick, having a direct confrontation with the doctors, which was reflected in newspapers and magazines of the time.
\end{abstract}

KeYswords: Hospital, Lima, healthiness, hygiene, Sisters of Charity 
«La Sociedad de Beneficencia es incapaz de corresponder al objeto para que ha sido creada; compuesta de personas estrañas (sic) a la Medicina, debe sin embargo ocuparse de las funciones más elevadas de esta ciencia».

Francisco Rosas

Gaceta Médica de Lima, 30 noviembre 1858

\section{Estado de Lima a mediados de 1850}

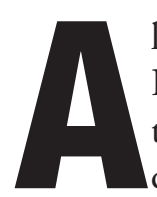
1 iniciarse la segunda mitad del siglo XIX, el Perú había soportado continuas luchas internas, dirigidas por los militares que defendieron al Perú, contra la corona española, pero hoy se enfrentaban entre ellos, esto se agudizo aún más con las guerras externas (Guerra con la Gran Colombia, guerra con Bolivia, Confederación peruana, boliviana). Estos continuos enfrentamientos ocasionaron a la vez que el país, permanezca en una aguda crisis política, social y económica, iniciada incluso desde los primeros ańos de declarada nuestra independencia, 1821. Esta vorágine nacional repercutió en todo el incipiente estado peruano

Como ejemplo de este arcaico lujo podemos leer «... Lima era reina de las ciudades sudamericanas orgullo del hemisferio occidental, donde el virrey sobrepasa en boato a los monarcas europeos, donde los comerciantes eran celebres por su opulencia, donde las ciencias y artes y el comercio florecían. Ay -tempora mutantur- que cambio. La desoladora y larga guerra civil habían puesto su mano férrea en la ciudad antes dichosa, y cuando la visite, en 1827 , que triste contraste representaba. El nuevo gobierno en bancarrota y necesitado, los comerciantes insolventes, desaparecida la confianza, los templos despojados, vendidos los adornos de los habitantes, gente que vivía en palacios reducida a pobreza absoluta». ${ }^{1}$

Mientras que el gobierno central estaba sumido en miles de problemas, las ciudades y por lo tanto su ente estatal, las municipalidades, acusaban una mayor penuria sin fondos y sin cumplir sus requerimientos, más aun que desde 1839 estuvieron suprimidas, con algunos años de apertura, en donde el cargo dependía más de la autoridad gubernamental que de la misma municipalidad y será recién que en 1856 se restablecerían las municipalidades ${ }^{2}$.

El común denominador de las municipalidades fueron los escasos recursos, lo cual no les permitía cumplir con su labor de cuidado ordenamiento y ornato de la ciudad, "estando reducido aun en la capital misma de la republica a lo más indispensable y rudimentario $»^{3}$

Pero no solamente era la Municipalidad de Lima la que sufría esas penurias, podemos imaginarnos lo que pasaba con otras instituciones, como por ejemplo con la Sociedad de Beneficencia Pública de Lima, ministerios y con la misma Universidad San Marcos, las cuales sufrían agobiantes crisis institucionales.

Todas estas tragedias cambiaran radicalmente para el Perú, con el ingreso en la política nacional del Mariscal Ramón Castilla, quien gobernaría el país en dos periodos (1845-1851 y 1855-1862). Con Castilla se inició un periodo de paz y prosperidad así como de bienestar material, esto gracias a la explotación del guano y del salitre lo cual permitió, entre otras cosas tener un presupuesto bien elaborado, un ejército mejor pagado, así como desarrollar diversas obras a lo largo y ancho de todo el país y con mayor énfasis en la ciudad de Lima, la cual poco a poco fue fiel reflejo de esta "prosperidad falaz»

\section{La Sociedad de Beneficencia de Lima y sus orígenes}

Desde sus orígenes, la asistencia, siempre estuvo cargada de un fuerte tufo de la caridad cristiana, la cual pregonaba que al ayudar en este mundo terrenal a los desvalidos, esto serviría para que en el más allá, uno sea considerado. Lima al igual que todas las ciudades hispanas eran eminentemente católicas caracterizadas por el valor de la caridad como un deber cristiano, formador además de la moral del «buen ciudadano». ${ }^{4}$

Esta asistencia estuvo siempre dirigida por la elite limeña y para el caso de las provincias, por las elites provinciales, quienes se agruparon en sociedades caritativas «Beneficencia».

Desde sus origines la Sociedad de Beneficencia se preocupó por dar asistencia a los más necesitados tan-

\footnotetext{
El Monitor Médico, numero 1 junio de 1885.

El Monitor Médico, numero 2 junio de 1885.

$4 \quad$ Ponce de León (2011: 48).
} 
to a nivel educativo, (pues se encargaban de la educación básica) como a nivel curativo (veían el funcionamiento de los hospitales y su misma administración). Igualmente administraban el servicio del Cementerio General de Lima. Posteriormente se harán cargo del control administrativo de las cárceles y de la dirección y vigilancia de los colegios de instrucción primaria ${ }^{5} \mathrm{y}$ en 1865 administraran las rentas de las cofradías para subrogarlas en su misión humanitaria ${ }^{6}$

Los orígenes de la Sociedad de Beneficencia de Lima, se remontan hasta el 17 de junio de 1834 , gobernaba por aquel entonces, el Mariscal José Luis de Orbegoso. La Beneficencia de Lima era una institución netamente caritativa, la cual ejercía un fuerte control social y moral, esta institución obtenía variadas donaciones, en capital y en propiedades, las cuales luego eran arrendadas obteniendo grandes réditos, a la vez obtenía ingresos gracias al Ramo de Loterías, la Caja de Ahorros y el arriendo de la Plaza de Toros en Acho.

A la vez dirigía la lucha por la higiene y sanidad de la ciudad, la cual era muy lamentable, enfrentando las epidemias que azolaron Lima, como el Colera Morbus de 1837, viruela en 1839 y 1845 , fiebre amarilla 1868 .

Algo que siempre estuvo presente y ligado a la Beneficencia de Lima, fueron los hospitales, ya que no existía una dirección de salud independiente y más aún se contaba con escasos recursos económicos, al ser fundada la Beneficencia, esta coge las rentas de las vetustas instituciones de caridad, las cuales subsistían desde tiempos virreinales ${ }^{7}$,

Pero que individuos formaban parte de la Beneficencia de Lima, esta al igual que otros países latinoamericanos ${ }^{8}$ estuvo integrada por una «elite

\footnotetext{
Grańa 1945:779

Gunther y Lohman 1992:191

Los hospitales eran dueños de diversos predios rústicos y urbanos y con sus ventas y alquileres se obtenían fuertes suma de dinero, asimismo existía el impuesto llamado tomin de Hospital, la sisa, que era un impuesto a la venta de carnes; igualmente algunos hospitales obtenían diezmos, primicias, donaciones particulares y otros ingresos los cuales variaban de cantidad, por eso variaba la economía de esta institución de ayuda social

8 Para el caso chileno puede consultarse, Orígenes y desarrollo de la Beneficencia Pública en Chile. Estevan Ivovich e Isauro Torres; Imprenta Universitaria. Santiago de Chile 1932. La Beneficencia Pública en Chile. Edo. Castillo Velasco; Universidad Católica de Chile. 1937. Gobernar la Pobreza. Prácticas de caridad y beneficencia en la ciudad de Santiago 1830-1890. Macarena Ponce de León. DIBAM, 2011.
}

religiosa» y con un alto precepto de colaboración y ayuda mutua hacia el prójimo. En las diversas memorias consultadas de la Beneficencia uno podrá enterarse de quienes eran sus miembros, denominados en muchos casos "Benefactores», entre los principales podríamos mencionar rápidamente al Presbítero Matías Maestro, quien distribuyo su fortuna entre varias instituciones piadosas y construyo el Cementerio General de Lima, así como la antigua Escuela de Medicina de San Fernando', asimismo fue Director General de la Beneficencia de Lima. Doña María Luisa López Maturana de Jacot, Condesa de Pozos Dulces, quien otorgo por testamento en Madrid varias fincas al Hospital de la Caridad de Lima. En 1850 Juan Ruiz Dávila y Hazańa Palacio, fundador del Hospicio para Señoras pobres y viudas de comerciantes ${ }^{10} .1850$ Antonio Chacón, bajo cuya administración, se realizaran grandes cambios estructurales a los principales hospitales limeños. 1855 Coronel Juan Nepomuceno Vargas, quien fundo la Casa de Guadalupe, para mujeres pobres. 1866 Pedro González de Candamo quien lego una fuerte cantidad de dinero para fundar el Colegio y Hospicio de Santa Rosa. 1871 Jerónimo de Agüero, dejo sus cuantiosos bienes a la misma institución. 1872 Bartolomé Manrique, construyo un hospicio para señoras pobres ${ }^{11}$ cubriendo todos los gastos bajo su propia fortuna. Francisco Carassa quien fuera varias veces presidente de la beneficencia, logrando grandes alcances en el desarrollo institucional. Por último, pero no menos importante podríamos mencionar al gran benefactor José Sevilla quien dueño de una gran fortuna, dejo gran cantidad de la misma, para que sea administrada por la misma beneficencia, creando incluso una escuela básica de educación para niñas en Lima, conocida como Instituto Sevilla ${ }^{12}$.

La Sociedad de Beneficencia, administraba para mediados del siglo XIX a los siguientes hospitales, Hospital de San Andrés, dedicado a la atención de hombres; Hospital de Santa Ana, dedicado exclusivamente para tratar a las mujeres; Hospital de San

9 Eguiguren 1946: 115.

10 Comúnmente conocido como Hospicio Ruiz Dávila, ubicado en la cuadra 5 del Jr. Ancash. Este albergue brindaba vivienda a familias enteras así como a mujeres, pero hoy sirve para mantener más oficinas burocráticas del Congreso de la República.

11 El Hospicio Manrique hoy se encuentra en el mismo lugar que fuera fundado, antigua Plaza de la Recoleta, hoy actual Plaza Francia.

12 Coello (2007) 
Bartolomé que se encargaría de tratar a los militares. Sendos hospitales estaban situados en la Plaza San Ana en pleno centro de Lima y venían funcionando desde épocas coloniales, lo cual los convertía en hospitales obsoletos razón por la cual no estaban preparados para poder dar cobijo y ayuda a los cientos de pacientes que ingresaban diariamente a tratarse, más aun sus instalaciones estaban caducas y debido a las constantes epidemias se saturaban rápidamente, lo cual los convertía en centros antihigiénicos, la población aumento, mientras que los hospitales al contrario estuvieron iguales desde los años coloniales, empero recién será hacia 1874 que Lima tendrá un nuevo hospital, nos referimos al Hospital Dos de Mayo, pero eso es otra historia.

Lo común para sendos hospitales era tener mala iluminación, escasa ventilación, pisos de tierra; mientras que en cuanto al material de uso diario (vajilla) así como la ropa de cama) era deplorable; todos estaban saturados de pacientes, era tal el estado de insalubridad de los hospitales que incluso fueron materia de reportajes periodísticos así como de tesis, en donde ya se alertaba sobre el pésimo estado que reinaba en dichos locales ${ }^{13}$

\section{Creación de la moderna Facultad de Medicina de San Fernando}

La actual Facultad de Medicina de San Fernando, fue inaugurada en tiempos del Virrey Fernando de Abascal hacia 1808, recibiendo el nombre de Colegio de Medicina y Cirugía de San Fernando. El primigenio local de dicha institución fue construido por el presbítero Matías Maestro y se inauguró en 1811, en la esquina de las calles de San Andrés y Sacramento de Santa Ana, frente a la plaza del mismo nombre (hoy actual Plaza Italia), La ventaja de esta escuela, es que se hallaba colindante al Hospital de San Andrés, así como contigua a los de Santa Ana y San Bartolomé.

Para comprender los orígenes así como el desarrollo histórico de la Facultad de Medicina de San

13 Nuñez del Prado D., Podredumbre de Hospital (1863). Lorena, A. Higiene de Hospitales (1877); Huapaya G., Podredumbre de Hospital (1877).
Fernando se puede consultar la siguiente bibliografía especializada ${ }^{14}$.

Luego de declarada la independencia hacia 1821, el antiguo Colegio de Medicina y Cirugía de San Fernando, cambiara de nombre, por el de Colegio de la Independencia ${ }^{15}$, este centro de investigación atravesó continuas crisis económicas e institucionales, «Las penurias económicas trajeron muy pronto perturbación en su funcionamiento, que se reflejó en la disciplina, y es bastante para tener idea de las deficiencias que tuvo en el la enseñanza desde la iniciación de la Republica, a los diez u once años de su fundación, hasta $1842{ }^{16}$. Igualmente el investigador Valdizán, se ratifica en las continuas crisis y nos dice que entre los años 1821 y 1855 , hubo años de clausura y ańos durante los cuales el Instituto hizo una vida tan precaria que parecía amenazar una eminente extinción. ${ }^{17}$

En setiembre de 1856 se oficializara la conversión del Colegio de la Independencia en la recientemente creada Facultad de Medicina, por entonces gobierna el Perú el Presidente Constitucional, Ramón Castilla, él promulgará el Reglamento institucional de la Facultad de Medicina, la cual será la pionera en el estudio de medicina en el Perú, así como un gran foco de prestigio científico en américa del sur.

La recientemente creada Facultad de Medicina poco a poco ira gozando de un gran poder institucional, así mismo sus futuros médicos serán considerados los nuevos ilustrados de esta ciudad, una micro elite científica, ellos opinaran en diversos temas de política nacional, así como en los temas específicamente relacionados a su especialidad, como ornato, salud e higiene de la ciudad y de los hospitales. Incluso se atreverán a más, pues muchos de aquellos novatos médicos eran burgueses y muchos eran miembros del recientemente Partido Civil, otros ingresaran al Congreso de la República ${ }^{18}$ donde mantendrán una

14 Historia de la Medicina Peruana Juan B. Lastres. UNMSM, Lima 1951, Hospitales de Lima Colonial Siglos XVII-XIX. Ilder Mendieta Ocampo, Seminario de Historia Rural Andina. UNMSM, Lima 1990. Medicina y Salubridad en el Siglo XIX. Alejandro Salinas Sánchez, Seminario de Historia Rural Andina. UNMSM, Lima 2000. «El antiguo Hospital Real de San Andrés de Lima» Antonio Coello Rodríguez. En Arkinka. Año 7, número 84, Lima 2002.

15 Uriel García 2004: 52

16 Olaechea 1933: 624

17 Cf. Valdizán 1925.

18 José Mariano Macedo (1823-1894) representante al Congreso nacional por Puno. José Casimiro Ulloa (1829-1891) elegido varias 
fuerte actividad política, mientras que otros desplegaran una labor periodística, escribiendo en diversos diarios locales ora en revistas y hasta en publicaciones científicas ${ }^{19}$.

$\mathrm{El}$ «control médico» desde entonces será una especie de nueva inquisición aunque claro sin caer en el extremo de quemar brujas, pero si se encargaran de velar por el desarrollo de la especialización y profesionalismo médico. Tal como se da este fenómeno en Perú, sucederán estos cambios en otros lugares incluso muy distantes, Foucault (1977), reporta para Londres una serie de reacciones violentas de parte del pueblo, ocasionadas por pequeñas insurrecciones anti médicas, ocurridas en la segunda mitad del siglo XIX.

Pese a que el cuerpo médico no gozaba del aprecio popular, el estado peruano respaldo toda acción tomada por los galenos, aquí podríamos asumir que sucedió lo planteado por Foucault «La organización de un saber medico estatal, la normalización de la profesión médica, la subordinación de los médicos a una administración general y, por último, la integración de varios médicos en una organización medico estatal, llevan aparejados una serie de fenómenos enteramente nuevos que caracterizan lo que podría denominarse medicina de Estado» (1978: 43).

Si trasponemos esta cita a la realidad peruana del aquel entonces tendremos que la administración general en este caso, será aquí la recientemente convertida Escuela de Medicina (San Fernando) en Facultad de Medicina de Lima.

veces parlamentario. Celso Bambaren (1834-1897), representante al congreso por Ancash. Miguel Colunga (1836-1914), diputado por Lima. Lino Alarco (1835-1903), Vicepresidente del Perú, en 1903 durante el Gobierno de Nicolás de Piérola

19 José Casimiro Ulloa (1829-1891), mantendrá una agitada vida literaria, colaborador de diversos medios escritos, como Gaceta Médica de Lima, la Gaceta Judicial, Monitor Médico, El Rímac, El Nacional, El Comercio, La Revista de Lima. José Sebastián Barranca (1832-1909) prestigioso médico y botánico. Considerado un humanista total, realizo una traducción del drama Ollantay del quechua al castellano. Miguel E. Colunga (1836-1914) escribió interesantes trabajos sobre botánica y zoología. Pablo Patrón 1854-1910) gran colaborador de la Crónica Médica, en donde escribió temas netamente médicos, así como trabajos de historia peruana, entre los que podemos mencionar La sucesión de los Incas, Lima antigua, Origen del quechua y del aimara . Leonardo Villar (1825-1900) conspicuo colaborador de la Gaceta Medica de Lima. José Mariano Macedo (1823-1894) gran erudito, su conocimiento abarco las ciencias médicas, humanidades y sociales, realizo diversas expediciones arqueológicas y formo una gran colección de piezas prehispánicas, muchas de ellas hoy se hallan en museos alemanes. Mariano Arosemena Quesada (1818-1883), de origen panameńo pero realizo sus estudios médicos en la Facultad de San Fernando, publicó numerosos trabajos sobre medicina legal, higiene y terapéutica médica.
La agremiación médica, no solamente estuvo integrada por médicos, sino también por dentistas, farmacéuticos, parteras y flebotomianos, estos se hallaban unidos profesionalmente, además de estar unidos por otros lazos como participar en el bien común de la misma sociedad de ayuda mutua, lazos de mutualismo, bienestar económico, social y educativo ${ }^{20}$

La Facultad de Medicina y la profesión médica, poco a poco adquieren un rol protagónico dentro de la sociedad limeña, el mismo que finalizo abruptamente con la Guerra del Pacifico (1879-1883) y la invasión y derrota peruana, por el ejército chileno, cortando así el gran desarrollo científico, que se venía desarrollando.

Es así que poco a poco amparándose en el desarrollo de la ciencia médica, los galenos trataran de tomar el control de los hospitales, pero para poder ganar esta batalla tenían al frente a una institución muy bien organizada y de antiguo abolengo, la cual existió desde los inicios de la república y estuvo ocupada por la elite limeña, sin embargo la misma no era una elite científica ni ilustrada, tan solo una elite económica, nos referimos a la Sociedad de Beneficencia de Lima.

Este enfrentamiento al igual que sucedió en Lima, se repitió en Santiago de Chile, en donde se enfrentaron la medicina por un lado contra la beneficencia apoyadas además por las Hermanas de la Caridad, es decir una pugna entre lo científico y lo caritativo.

Para enfrentar esta guerra que tenía como objetivo ilustrar al pueblo, en cuanto a los beneficios de ser dirigidos por el cuerpo médico, dirigir la lucha contra la insalubridad, organizar la higienización de Lima y de ocupar los hospitales, los médicos utilizaran como armas, la prensa escrita, a través de los diarios capitalinos y de su revista especializada Gaceta Medica de Lima.

\section{El papel de la prensa médica y su publicación oficial}

Una vez ya institucionalizados, los médicos tendrán su órgano de prensa, la misma que vio la luz en la Ciudad de Lima el 15 de agosto de 1856, se le denomino Gaceta Médica de Lima. Órgano oficial de la Sociedad de Medicina ${ }^{21}$ ).

20 Forment 1999: 223

21 La Gaceta Medica de Lima, era la voz escrita y órgano oficial de la Sociedad de Medicina, fue su 1 Director Antonio Sánchez Almodóvar 
La Gaceta Médica de Lima fue una publicación eminentemente científica, de aparición quincenal, en donde los médicos opinaron tanto de temas específicamente médicos como temas de actualidad nacional (situación política de la nación, propuestas y recomendaciones sobre temas de higiene y salubridad para los habitantes limeńos, estado situacional de los hospitales, presencia de enfermedades y epidemias que azotaban Lima etc.). Aun aún no se ha valorado el enorme valor e importancia que tuvo esta gran revista científica para comprender la historia de la ciencia, así como de la misma historia del periodismo. La Gaceta Medica de Lima, tuvo una gran acogida a nivel nacional e internacional, pues tuvo corresponsales y suscriptores en diversas ciudades, tales como Valparaíso (Chile) Guayaquil (Ecuador); mientras que por el lado peruano tenia corresponsales en sus inicios en el Puerto del Callao, Arequipa, Tacna y posteriormente Cerro de Pasco y Trujillo.

La Facultad de Medicina de San Fernando y su publicación oficial Gaceta Médica de Lima, formaron un binomio de avanzada, pues una vez ya lograda la institucionalidad y profesionalismo poco a poco intervendrán en la vida cotidiana limeña, en cuatro aspectos generales $^{22}$ : 1 .- Autoridad reglamentada con peso fiscal y estatal, la misma que podrá tomar decisiones a nivel de la ciudad, barrio. 2.- Los médicos intervendrán no solamente en el campo de las enfermedades, sino también en lo relacionado a la construcción de nuevas viviendas, desagües, instalación de agua para el consumo humano, sistema de iluminación, sistema de calefacción, instalación de pisos, etc. 3.- Ocupacion hospitalaria, poco a poco el cuerpo galeno en los temas relacionados al desarrollo de los hospitales, opinara respecto a los alimentos, visitas médicas, vestuario, pero lo que nunca podrá hacer será en lo concerniente a la administración propiamente dicha, pues está siempre será regentada por la Sociedad de Beneficencia de Lima, la cual ampliara la libertad de opinión y profesional de los médicos, pero nunca dejara que los bienes económicos sean administrados por ellos. 4.- Introduccion de mecanismos de administración médica, lo cual no es otra cosa que el desarrollo de registros de ingreso y salida de los enfermos, así como comparación de los mis-

y sus redactores iniciales José Mariano Macedo, Francisco Rosas, José Casimiro Ulloa y Manuel N. Corpancho.

22 Cf. Foucault 1976: 27 mos, aparición de las visitas médicas y juntas médicas, donde debatirán las enfermedades y las acciones a tomar, esto llegara al cenit con la introducción de la ciencia estadística, la cual será considerada un arma letal y capaz de comprender el movimiento y conducir hacia el triunfo, ante las enfermedades ${ }^{23}$.

Durante el desarrollo histórico de los hospitales limeños, siempre existieron relaciones tensas entre la Sociedad de Beneficencia de Lima, encargada de administrar los hospitales de Lima, versus la Facultad de Medicina de Lima, la cual era la encargada de velar por el cuidado de los enfermos, pero querrá dirigir el control de los hospitales, pese a que tenga que estar bajo el poder de la Sociedad de Beneficencia de Lima, la cual veía el desenvolvimiento de los mismos, $\mathrm{Al}$ decir de Zarate (2005: 95) toda opinión elaborada por los médicos siempre será revisada por los ecónomos de la Sociedad de Beneficencia.

Es así que los médicos utilizaran su publicación oficial la Gaceta Medica para hacer llegar continuas quejas y críticas a la Sociedad de Beneficencia de Lima, en su accionar para con los hospitales, sin embargo no todo será negativo, también habrá palabras estimulantes relacionadas a la higienización de Lima.

Por ejemplo en la edición número 4 de la Gaceta Médica de Lima, se da la primera alerta sobre la situación hospitalaria de Lima y los cambios que deben aplicarse a esta, pues se pide que los médicos ingresen a atender a los enfermos.

De los estudiantes más adelantados que hoy cuenta el Colegio de Medicina, se nombrara un alumno interno y dos externos para cada departamento; los primeros con el cargo de desempeñar todas las obligaciones y los segundos encargados de la distribución de bebidas y curaciones. Para las ocurrencias apremiantes y graves que puedan ocurrir en la noche se dispone que un médico auxiliar duerma en el hospital. Ellos están obligados a prestar sus servicios profesionales a cualquier hora de la noche, cuando la gravedad y urgencia del caso así lo requieran ${ }^{24}$.

\footnotetext{
23 En variadas publicaciones de la Gaceta Médica, se presentan diversos cuadros estadísticos de las enfermedades ocurridas en Lima, así como en los hospitales, también se darán a conocer las estadísticas de nacimiento y mortandad de la ciudad de Lima. Ver la Revista Médica de Lima del 15 de agosto de 1856 «No son menos importantes los servicios que la estadística medica esta llamada a prestar a la ciencia y a la humanidad, ni menos provechosa los resultados que con ella debemos obtener en el curso de nuestras operaciones».

24 Cf. Gaceta Médica de Lima, 30 de setiembre de 1856. Artículo «Crónica de Hospitales», escrito por J. M. Macedo
} 
Algo común, en la publicación era dar la noticia reiterativa sobre el estado de insalubridad general que asolaba a Lima, más aun cuando se hacía presente una epidemia, recordemos que la ciudad de Lima sufrió de constantes epidemias a lo largo de toda su vida colonial y republicana, que incluso quedaron registradas en diarios y revistas; entre las que podemos mencionar a la de viruela, gripe, fiebre amarilla, $(1856,1863,1867,1868,1875,1877) .{ }^{25}$

Igualmente en diversos números de la revista, se tratara temas de la vida diaria como higiene publica, el agua y las acequias limeñas ${ }^{26}$ el servicio de alumbrado por gas $^{27}$, el tipo de habitaciones que debían ocuparse $^{28}$.

Siguiendo con el enfrentamiento entre la Sociedad de Beneficencia de Lima y el cuerpo médico. En la publicación número 31 de diciembre de 1857 se hace una fuerte crítica al sistema hospitalario, así como a la institución misma, a la vez se plantea la solución para poder corregir el estado de insalubridad de los hospitales y poder organizar una nueva administración, liderada por un cuerpo especializado.

«Es preciso, pues, que esa organización caduca, [Beneficencia] que ahora la desvirtúa y que frecuentemente la precipita en el mal, desaparezca para dar lugar a otras más conforme con la ciencia y la justicia. El ejemplo de los pueblos más civilizados y el sentido común enseñan, que la dirección de los hospitales, de las casas de locos y de huérfanos; y en general, casi todas las cuestiones que se suscitan en el seno de la Sociedad de Beneficencia son de la exclusiva competencia de los médicos: abandonemolas, (sic) pues a ellos y solo a ellos.»

Continuando con la misma editorial y de manera más furibunda se lee «... a nadie se oculta cuanto ha influido la Sociedad de Beneficencia en el atraso de los hospitales y de los hospicios, cuantos males ha causado, cuantos desaciertos ha cometido, y cuánto dinero ha gastado inútilmente» el énfasis es nuestro.

Posteriormente, luego de mucho batallar, se leerá en La Gaceta Médica los grandes cambios para mejo-

25 Para seguir cronológicamente una historia de las epidemias que asolaron Lima podemos consultar entre otros a "Las epidemias en Lima durante el siglo XIX»; 1910. Polo J. Apuntes sobre las Epidemias en el Perú, 1919. Lastres, J. «Terremotos, hospitales y epidemias de la Lima coloniali; 1940.

26 Gaceta Médica de Lima, número 6 y 8, 1856; numero 26 de 1857.

27 Gaceta Médica de Lima, número 9, 1856.

28 Gaceta Médica de Lima, número 10 de 1856 y 11 de 1857. ras ocurridos en los hospitales de Lima y que fueron generados por los propios galenos, estos cambios estuvieron relacionados a la destrucción de las antiguas covachas e introducción de catres de fierro, apertura de grandes teatinas en los techos, lo cual permitió que circule un aire limpio y puro ${ }^{29}$, con estos cambios estructurales, los hospitales hicieron que la estadía en ellos sea algo mejor e incluso más alegre para con los pacientes, un ańo después en la misma Gaceta, se dará una mejor noticia para el servicio de los hospitales, la cual trataba sobre el aumento en el número de camas, la instalación del servicio de alumbrado a gas, colocación de pisos de asfalto o conocido también como betún, en reemplazo de los apisonados o pisos de tierra, lo cual con el transito continuo ocasionaba un fuerte polvo al interior de las salas de enfermos (octubre de 1859).

Estos logros alcanzados por la comunidad médica, les permitió alcanzar otro gran logro, nos referimos aquí a la inauguración del Hospital de la Misericordia, conocido también como Hospital de Amentes ${ }^{30}$, Manicomio del Cercado o Manicomio de Lima, sucedido el 16 de diciembre de 1859, ubicado en pleno corazón del Barrio de Santiago del Cercado, Lima. La construcción de este nuevo edificio estuvo dirigida por el Arquitecto Cluzeau, arquitecto de la Beneficencia de Lima y fue su primer Director y a la vez fundador el Doctor José Casimiro Ulloa; eminente médico peruano, preocupado por ordenar el sistema hospitalario y dotar a la ciudad de Lima de un sistema de higienización saludable.

José Casimiro Ulloa ${ }^{31}$ junto a otros jóvenes médicos peruanos (Francisco Rosas, Rafael Benavides, Celso Bambaren, Camilo Segura) recién egresados y en otros casos aun estudiantes tuvieron la dicha de viajar a estudiar a Francia, ellos fueron enviados por el Gobierno Peruano del mariscal Castilla y aprovechando la disposición de Cayetano Heredia, quien era Rector del entonces Colegio de la Independencia

29 Gaceta Médica de Lima, número 40 de 1858.

30 Para una historia del Manicomio de Lima puede consultarse entre otros, los trabajos de Stucchi-Portocarrero Santiago «El tratamiento moral y los inicios del manicomio en el Perú» 2015. Ruiz Augusto «Medicina mental y modernización: Lima, 1850-1900» (1995). Coello Antonio «El Hospital de Amentes. El primer manicomio para la ciudad de Lima, 1859» (2018).

31 Para una biografía y obra de Jose Casimiro Ulloa, puede consultarse "Jose Casimiro Ulloa Bucelo 1829-1891. El Paladin del gremio Médico" Salaverry O. 2010. 
y que después sería conocida como Facultad de Medicina.

La misión de estos bisoños galenos era la de perfeccionarse y traer al Perú, los últimos avances científicos para luego ponerlos en práctica; es así que José Casimiro Ulloa al regresar a Lima puso en ejercicio todos sus conocimientos para el futuro manicomio u Hospital de Amentes, el mismo que conto con todos los adelantos de aquella época para tratar a los pacientes «locos» del moderno nosocomio, el cual contaría con baños de agua tibia, habitaciones limpias y aseadas, servicio de lavandería, ropa, comedor, etc. Para una mejor comprensión y descripción del edificio, puede consultarse la Gaceta Médica de Lima del 31 de diciembre de 1859; sin embargo algo con lo que no pudieron lidiar, fue que el cuidado de los pacientes estaría regentado por las mismas Hermanas de la Caridad, las cuales recién habían arribado al Perú, en 1856 para hacerse cargo de los establecimientos de salud y que eran regentados por la Sociedad de Beneficencia de Lima, con lo cual esta batalla ideológica estaría representada desde ahora por la Sociedad de Beneficencia de Lima, ayudada por las Hermanas de la Caridad, es decir la caridad cristiana por un lado, frente a la ciencia, representada por la Facultad de Medicina y su órgano de prensa, la Gaceta Médica de Lima.

\section{Las Hermanas de la Caridad y su llegada al Perú}

La llegada al Perú de las Hermanas de la Caridad fue anunciada a la alta sociedad limeña en la Memoria anual de la Sociedad de Beneficencia de 1856, las cuales venían del país sureño de Chile ${ }^{32}$, en donde ya habían tenido una larga experiencia cuidando enfermos y dando cobijo a pobres y desamparados, esta práctica de tratar enfermos ya había tenido una larga data en América, pues incluso antes de Chile ya lo habían hecho en México ${ }^{33}$, así que entendían ya muy bien la idiosincrasia americana y más aun no tendrían ningún problema con el idioma castellano.

Pero que funciones cumplirían las Hermanas de la Caridad, aparte de cuidar y velar a los pacientes y enfermos de todos los hospitales, pues se harían

32 A dicho país, ya habían ingresado a inicios de la década de 1850

33 1844, durante el Gobierno del dictador Santa Ana. cargo de la preparación de los remedios solicitados así como de la comercialización de los mismos en las diferentes boticas ubicadas al interior de cada uno de los hospitales. Para el caso particular de Lima «la ropería» también estaría confiada al cuidado de ellas pues es una de las dependencias del hospital que da una idea favorable del orden y aseo que ellas dan ${ }^{34}$.

Otro problema que suscito la llegada de las hermanas a Lima, fue el saber, donde vivirían y quien solventaría sus gastos. Es así que el estado autorizo a la Sociedad de Beneficencia de Lima el 3 abril 1856, para que se contrate, traslade y entregue a las Hermanas de la Caridad de San Vicente de Paul, los establecimientos que corren a su cargo.

Durante la larga estadía de las Hermanas de la Caridad en el Perú, se desarrolló un agitado enfrentamiento ideológico entre los defensores de la causa (Sociedad de Beneficencia de Lima), pues ellos explicaban el beneficio que traerían las hermanas para el bien y cuidado de los hospitales, contra los detractores de la misma, (Facultad de Medicina de San Fernando) para quienes las monjas no estaban capacitadas para hacerse cargo ni de los hospitales, sus boticas y menos del cuidado y tratamiento de los pacientes. Sin embargo la población limeña, que solo entendía de caridad y ayuda, si aceptaba muy bien la labor desarrollada por las Hermanas de la Caridad.

Este duro debate dado en el Perú, tuvo semejantes opiniones a favor y en contra, tanto en México, como en Chile, más aun cuando en toda América, existía el fuerte debate entre si seguir siendo republicas subordinadas al poder de Roma, o republicas laicas. Para el caso de México «no faltaron acusaciones contra ellas de que robaban, maltrataban, regañaban, eran extranjeras y mochas, cuando más bien daban lo que no tenían y lo que no también" ${ }^{35}$

Así se daba a conocer el papel caritativo y el bien que prestarían para con nuestra ciudad, «La adopción por el Perú de la caritativa congregación de las Hermanas de San Vicente, ha venido a dar la última mano a este servicio y a poner a nuestros hospitales en tal estado que no avergonzarían a muchas ciudades del viejo continente. Las Hermanas de la Caridad han coronado los constantes esfuerzos de la Sociedad de Beneficencia, y han operado ciertamente en las ca-

34 Cf. Memoria anual de la Beneficencia 1857-1858.

35 Malvido 2004: 437. 
sas que se han puesto bajo su dirección una verdadera metamorfosis, reemplazando el servicio estipendiado y mercenario que allí se hacía, por el servicio de evangélica caridad que su institución estaba llamada a desempeñar». ${ }^{36}$

La Gaceta Médica de Lima tomara parte activa en este enfrentamiento, en un inicio y debido creemos al desconocimiento y labor específica de las hermanas fue de respaldo y admiración. Han llegado las Hermanas de la Caridad tanto tiempo esperadas. La introducción de estas piadosas mujeres, producirá en nuestros hospitales, una reforma saludable a la ciencia. Desde hoy podrán descansar los médicos tranquilos con la seguridad de que sus prescripciones serán ejecutadas con la severidad que demanda la ciencia. Felicitamos a la Sociedad de Beneficencia por esta medida de tan provechosa transcendencia ${ }^{37}$.

Posteriormente, la opinión favorable será convertida en una fuerte crítica, tal como puede verse en la editorial del 15 de octubre de $1858^{38}$, en donde se critica la facultad dada por la Sociedad de Beneficencia para que las Hermanas de la Caridad administren la botica del Hospital de Santa Ana, sin la intervención de ningún farmacéutico. Los médicos se sienten respaldados pues según las leyes de aquel entonces, las boticas no pueden ser administradas por personas que no posean títulos. Los médicos critican esta acción copiada de Chile, en donde las boticas son administradas por las Hermanas de la Caridad y al decir de los galenos nacionales, "Chile es un pueblo atrasado que apenas comienza a hacer ensayos, especialmente en el orden científico, y que por lo mismo no puede concedérsele autoridad ninguna» (edición número 52, de 1858). Posteriormente la Sociedad de Beneficencia ampliara esta concesión para el Hospital de San Andrés, ocasionando un mayor pesar a los médicos.

En otra publicación, de febrero de 1859 la Gaceta Medica de Lima, seguirá criticando a las Hermanas de la Caridad acusándolas de falta de dulzura en el trato con los enfermos, de indiferencia y de abandono con ellos, así como a la falta absoluta de asistencia hacia los pacientes, sobre todo durante la noche.

Sin embargo la contraposición fue ejercida por la Sociedad de Beneficencia de Lima, quien enalteció la

36 La Revista de Lima, Tomo 1, junio 1860: 407.

37 Cf. Gaceta Médica, número 35, 1858.

38 Cf. Gaceta Médica, números 50 y 51, 1858. labor de caridad y ayuda al prójimo realizada por las Hermanas de la Caridad, tal como se puede leerse en esta apología: «... los servicios de estas Hermanas de la Caridad son de un orden muy superior al de las cosas de este mundo. Del cielo les vienen sus preceptos, y en el cielo serán juzgadas y premiadas». ${ }^{39}$

Asimismo, la Sociedad de Beneficencia en todas sus memorias anuales dará a conocer la encomiable labor de las hermanas, como en la Memoria anual de 1857-1858, en donde se anuncia que en el Hospital de San Andrés, alojara a 30 Hermanas de la Caridad «con las dependencias necesarias a su cómoda e independencia instalación, comunicando directamente e interiormente con las salas del Hospital y con la iglesia, dejando así satisfechas todas las exigencias de su servicio hospitalario y de sus deberes religiosos».

Posteriormente en la Memoria anual de 1864, la Beneficencia protege de toda calumnia a las Hermanas de la Caridad, quienes no obstante de haber sido encargadas de manejar las boticas, siguen soportando un mal trato y prejuicios. ${ }^{40}$

En la Memoria de la Sociedad de Beneficencia de 1866, presenta un panegírico a las mujeres caritativas y fuertes, que incluso se desarrollan en un ambiente hostil y a veces no entendido por los hombres de ciencia: «Debo, pues, hacer un acto de justicia a las Hermanas de la Caridad, principal resorte que comunica movimiento a cada una de esas máquinas, que les está encomendada, y les da vigor y regularidad en sus funciones, y para decirlo de una vez, son el principio de orden, economía y moralidad, infiltrada en el régimen de cada hospital, y en los demás. Establecimientos puestos a su cuidado».

Junto a estas publicaciones oficiales, tenemos la opinión del ciudadano común y corriente, que tan solo se preocupaba de trabajar y velar por su familia y que no se vea afectada por ninguna enfermedad o carencia de alimentos, esta opinión aparecía en los diarios locales y daba noticias sobre el enfrentamiento entre la ciencia y la caridad, en este caso mostraremos un claro ejemplo de respeto y admiración hacia las Hermanas de la Caridad, nos referimos específicamente al soneto aparecido en el diario El Nacional en homenaje a las hermanas y que decía:

39 Colección de Leyes, Decretos y Órdenes publicadas en el Perú, 1862: 292.

40 Cf. Memoria de la Sociedad de Beneficencia 1864. 


\section{LAS HERMANAS DE LA CARIDAD ${ }^{41}$}

Feliz el niño que en vosotras mora

Y educación cristiana aquí recibe,

Y del vicio y la ignorancia en donde vive

A la vida social renace ahora.

Todo el que sufre protección implora

Y si halla un corazón que se lo esquive

El consuelo en vosotras lo percibe,

Y en vez de pena de contento llora.

El pecho se conmueve enternecido

Al veros consolar en su amargura

$\mathrm{Al}$ enfermo y al pobre desvalido,

$\mathrm{Y}$ a tanta desgraciada criatura,

En cuyas almas tiernas ha infundido

Amor a la virtud, vuestra ternura.

J. L. de E.

Ante estos enfrentamientos tan marcados, prontamente el Ministerio de Justicia, Culto, Instrucción y Beneficencia comunica "Teniendo en consideración que las disposiciones legales relativas a que las boticas sean administradas por profesores de farmacia, no sufren detrimento, desde que las hermanas de caridad que hoy administran la de los hospitales están en el ejercicio de sus funciones, bajo la inmediata dirección y vigilancia de un inspector nombrado por la Beneficencia, de la clase de profesores examinados; se resuelve: que la administración de las boticas de los hospitales que corren a cargo de la Beneficencia continúen de la manera que actualmente se hallan, hasta nueva disposición del gobierno.» ${ }^{42}$

Este enfrentamiento bizantino, continuo por muchos ańos más, sin embargo reiteramos que el pueblo siempre confió ciegamente en el legado y ayuda desinteresada de las Hermanas de la Caridad, las cuales continuaron ayudando en los diversos hospitales limeños y hasta hoy lo siguen haciendo en el Hospital de enfermedades neurológicas Oscar Trellas, originalmente conocido como Hospital de Incurables.

\section{Conclusiones}

El presente trabajo de investigación explica cómo fue evolucionando el conocimiento científico durante la segunda mitad del siglo XIX, así mismo se analiza como apareció un poder científico representado por los médicos limeños y la recientemente creada Faculta de Medicina de Lima, antigua Escuela de Medicina fundada durante el virreinato

De la misma manera se analiza mediante diversos textos impresos del siglo xix los avances científicos de la medicina peruana y como esta se va empoderando de la situación nacional, con el fin de dirigir la lucha por la higienización y salubridad de la ciudad limeña

Con el transcurrir de la vida republicana aparecerá en la escena limeña la Sociedad de Beneficencia, ente caritativo encargado de administrar, dirigir y brindar los servicios de hospitalización y tratamiento para los enfermos, la Sociedad de Beneficencia se caracterizara por ser un ente regido de espiritualidad cristiana y de ayuda al prójimo pero carente de conocimiento científico.

Como parte del progreso y de la estabilidad política social, favorecida por una económica en ascenso, arribaran a Lima, las Hermanas de la Caridad de San Vicente de Paul, monjas procedentes de Francia, en donde tenían una tradición de ayuda hospitalaria. Al llegar a tierras peruanas, se les encomendara la misión de regentar los hospitales limeños, con lo cual se iniciara una lucha ideológica contra el cuerpo médico limeño y su ente gremial, la Facultad de Medicina, sendas instituciones entablaran una batalla ideológica manifestada en diversos medios escritos oficiales, así como en periódicos en donde cada uno plasmara su punto de vista y se considerará el único capaz de aliviar, comprender y dirigir las instituciones caritativas.

Este enfrentamiento repercutirá en la vida diaria limeña, pues habrán sectores de la población que apoyaran a unos y desacreditaran a otros, incluso habrán cartas afectivas a las Hermanas de la Caridad, mientras que por otro lado, los médicos harán relucir su conocimiento científico frente a una formación religiosa que solo se ampara en el amor al prójimo y en la caridad. 


\section{Bibliografía}

Anónimo (1860). Higiene pública. Apuntes dedicados a la Honorable Facultad de Medicina de esta capital. Lima: Tipografía del Comercio.

Fuster SÁnchez, Nicolás (2013). El cuerpo como máquina. La medicalización de la fuerza de trabajo en Chile. Santiago de Chile: CEIBO Ediciones.

Gaceta Médica de Lima, Órgano Oficial de la Sociedad de Medicina. Lima. Varios años.

García Cáceres, Uriel (2004). «Los orígenes de la Medicina Moderna en el Peru», en Enciclopedia Temática del Perú, Tomo XII SALUD. Lima.

Gunther, Juan y Lohmann Guillermo (1992). Lima Madrid: Colección MAPFRE.

Lastres, Juan (1951). Historia de la Medicina. La Medicina en la Republica, Vol. III. Lima: UNMSM.

Lossio, Jorge (2003). Acequias y Gallinazos. Salud ambiental en Lima del siglo XIX. Lima: IEP.

Malvido, Elsa (2004). Las Hermanas de la Caridad en México en el siglo XIX. El origen de la enfermería colonial. En: Enfermedad y muerte en América y Andalucia (Siglos XVI-XX). España: Consejo Superior de Investigaciones Científicas, pp. 427-444

Memoria de la Sociedad de Beneficencia Pública de Lima, varios años.

Pinto, Miguel y Candia Yolanda (2010). Curatos de Lima. Visitas eclesiásticas 1614-1915. Lima: SHRA-UNMSM.

PonCe De LeÓn, Macarena (2011). Gobernar la pobreza. Prácticas de caridad y beneficencia en la ciudad de Santiago, 1830-1890. Santiago: DIBAM.
Rabí Chara, Miguel (2006). Sociedad de Beneficencia de Lima Metropolitana. 172 años de Historia (1834-2006). Tomo VIII, Historia de la Medicina Peruana. Lima.

Ramón, Gabriel (1999). La Muralla y los Callejones. Intervención urbana y proyecto político en Lima durante la segunda mitad del siglo XIX. Lima: SIDEA.

Ruiz, Augusto (1995). Medicina mental y modernización: Lima, 1850-1900. En: Aldo Panfichi y Felipe Portocarrero Editores. Mundo Interiores: Lima 18501950. Lima: Universidad del Pacífico. p. 373-396.

Sociedad Peruana de Historia de la Medicina (1945). Vida y obra de José Mariano Macedo. Lima: San Martí y Cía. S.A.

Stucchi-Portocarrero, Santiago (2015). El tratamiento moral y los inicios del manicomio en el Perú. Revista de Neuropsiquiatria Vol. 78, n. 3, pp.153-158. Lima: Universidad Peruana Cayetano Heredia.

Oviedo, Juan (1862). Colección de Leyes, Decretos y Órdenes publicadas en el Perú, desde el año de 1821, hasta el 31 de diciembre de 1859. Tomo 8. Lima: Ministerio de Beneficencia, Instrucción pública y justicia. M.A. Fuentes, Editor.

Valdizán, Hermilio (1924). Publicaciones médicas del Doctor José Casimiro Ulloa. Lima

Zárate. Eduardo (2003). La construcción del poder médico en el siglo XIX. SITUA Revista de la Facultad de Medicina de la Universidad Mayor de San Marcos, número 21, pp. 9-15. Lima

Zárate. Eduardo (2005). Los inicios de la Escuela de Medicina de Lima. Lima: ANR. 